\title{
EL DIALOGUS DE ORATORIBUS Y LA OPINIÓN DE TÁCITO SOBRE LAS POSIBILIDADES DE LA ORATORIA EN EL RÉGIMEN IMPERIAL
}

\author{
D. SÁNChez VendRAmini \\ Centro de Estudios Históricos - CONICET \\ dnsanchez@gmail.com
}

\section{THE DIALOGUS DE ORATORIBUS AND TACITUS' OPINIONS ABOUT THE POSSIBILITIES OF ORATORY UNDER THE IMPERIAL REGIME}

La complejidad del debate creado por Tácito en el Dialogus de oratoribus ha generado una intensa discusión académica sobre las relaciones entre los argumentos presentados por los diferentes interlocutores y las ideas del propio autor respecto del desarrollo y las posibilidades de la oratoria bajo el régimen imperial. En el presente trabajo se intenta una aproximación a esta problemática diferente a las tradicionalmente presentadas. Más allá de los argumentos esgrimidos por los diferentes personajes de la obra, la atención se centra aquí en una serie de consensos subyacentes al debate que - puestos en relación con el conjunto de la obra del historiador romano- revelan interesantes facetas de la postura de Tácito sobre el tema central del diálogo.

Palabras clave: Tácito; Diálogo sobre los oradores; retórica.
The complexity of the fictive dialog created by Tacitus in the Dialogus de oratoribus has generated a lively scholarly debate about the relationships between the arguments presented by the different characters and Tacitus' own ideas about the development and possibilities of oratory under the imperial regime. In this paper a new approach to this problematic will be presented, different from other traditional approaches to the question. Beyond the different arguments presented by the characters of the work, attention will here be focused on some underlying points of consensus between them. This consensus, seen in relationship with all of the historian's works, reveals interesting new aspects of Tacitus' opinion about the central subject of the dialog.

Keywords: Tacitus; Dialog on orators; rhetoric.

La investigación especializada ha producido, en los últimos ciento veinte años, una casi inabarcable literatura sobre el Dialogus de oratoribus ${ }^{1}$. La

1 Orientativos sobre la vasta literatura en torno a esta obra son H. Merklin, «DialogusProbleme in der neueren Forschung. Überlieferunsgeschichte, Echtheitsbeweis und Umfang der Lücke», ANRW 2.33.3, 1991, pp. 2255-2283; D. Bo, Le principali problematiche del 
complejidad de este opúsculo ha generado un intenso debate académico. Uno de los aspectos más discutidos es la posible relación existente entre los argumentos presentados por los diferentes interlocutores de la obra y las ideas del propio autor respecto del desarrollo y las posibilidades de la oratoria en el régimen imperial. En el presente trabajo se intenta una aproximación a esta problemática, diferente a las tradicionalmente realizadas. Más allá de los argumentos esgrimidos por los diferentes interlocutores, se centra aquí la atención en una serie de consensos subyacentes al debate que, puestos en relación con el conjunto de la obra del historiador romano, revelan interesantes facetas de la postura de Tácito acerca del tema central del Dialogus.

Los indicios disponibles para determinar la datación del Dialogus de oratoribus son sumamente escasos. Todas las fechas probables o posibles han encontrado sus defensores, y muchas imposibles, también ${ }^{2}$. Un análisis acotado de la cuestión, como el realizado por C. O. Brink, llega a la siguiente conclusión: Tácito redactó el Dialogus, con toda probabilidad, en algún momento del período comprendido entre los años 99 y 103 de nuestra era $^{3}$. La datación del texto es importante, como veremos, a la hora de relacionar lo expuesto en el mismo con la biografía de Tácito.

Dialogus de Oratoribus, Zúrich, 1993. Véase también la serie de artículos bibliográficos de H. Benario, «Recent Work on Tacitus 1954-63», CW 58, 3, 1964, pp. 69-83; «Recent Work on Tacitus 1964-68», CW 63, 8, 1970, pp. 253-267; «Recent Work on Tacitus 1969-73», $C W 71,1,1977$, pp. 1-32; «Recent Work on Tacitus 1974-83», $C W$ 80, 2, 1986, pp. 73-147; «Recent Work on Tacitus 1984-93», CW 89, 2, 1995, pp. 91-162; «Recent Work on Tacitus 1994-2003», $C W$ 98, 3, 2005, pp. 251-336.

2 Para mencionar sólo las propuestas y trabajos más importantes: $a$ ) una fecha anterior al reinado de Domiciano: A. Gudeman, P. Cornelii Taciti Dialogus de Oratoribus, Leipzig- Berlín, $1914^{2}$, p. 29 ss.; b) una composición bajo Domiciano: W. Peterson, Cornelii Taciti Dialogus de Oratoribus, Oxford, 1893, p. XVIII; c) redacción de la obra durante el reinado de Nerva: C. E. Murgia, «The Date of Tacitus' Dialogus», HSPh 84, 1980, pp. 99-125; íd., «Pliny’s Letters and the Dialogus», HSPh 89, 1985, pp. 171-206; d) una fecha cercana a 101-102 d. C. o algo posterior es defendida, con diferentes matices, por: A. Kappelmacher, «Zur Abfassungszeit von Tacitus' Dialogus de oratoribus», WS 50, 1932, pp. 121-129, especialmente p. 127; K. Barwick, «Der Dialogus de oratoribus des Tacitus. Motive und Zeit seiner Entstehung», Sitzungsber. Sachs. Akad. zu Leipzig. Phil-hist. Kl., 101, 4, 1954, p. 31 ss.; R. Syme, «The Senator as Historian», Entretiens Fondation Hardt 4, 1956, p. 185 ss.; íd., Tacitus, Oxford, 1958, p. 671 ss.; R. Güngerich, «Tacitus' Dialogus und der Panegyricus des Plinius», Festschrift für B. Snell, Múnich, 1956, pp. 145-152; S. Borzsák, RE Suppl. 11, 1968, p. 433 ss.

3 C. O. Brink, «Can Tacitus' Dialogus Be Dated? Evidence and Historical Conclusions», HSPh 96, 1994, pp. 251-280. 
El Diálogo sobre los oradores comienza con una clara exposición de su tema. Tácito se prepara a dar repuesta a una pregunta, reiteradamente planteada por su amigo Fabio Justo, sobre las causas de la decadencia de la elocuencia contemporánea en comparación con aquélla del período final de la república, un tema al que hacen referencia numerosas fuentes del siglo $\mathrm{I}^{4}$. La forma dialógica elegida por el autor y el estilo utilizado, de tono ciceroniano, ubican la obra en un género literario determinado y con referentes precisos. Con un recurso narrativo típico de este género, Tácito afirma que no habrá de dar su propia respuesta al problema planteado sino tan sólo reproducir una discusión, a la que pudo asistir en su juventud, entre algunos de los talentos más destacados de la oratoria romana en el período inicial de la dinastía Flavia. Los protagonistas de la discusión son Marco Apro, Julio Secundo, Curiacio Materno y Vipstano Mesalla. Todos figuras históricas reales, pertenecientes al orden senatorial. El debate tiene lugar supuestamente en la casa de Materno, el día después de que éste (con la recitación de su tragedia Catón) hubiera generado malestar, según se comentaba en la ciudad, entre los círculos cercanos al poder. La fecha dramática del Diálogo se sitúa, entonces, en el reinado del emperador Vespasiano ${ }^{5}$.

El debate se inicia cuando Apro y Secundo intentan disuadir a Materno de su peligrosa vocación por las tragedias de tono político y convencerlo de que retome la más segura y ventajosa práctica de la elocuencia. Apro realiza entonces un encendido discurso contra la poesía y a favor de la oratoria como ocupación, mientras que Materno, a su vez, responde con un alegato contra la elocuencia y a favor de la poesía. La llegada repentina de Vipstano Mesalla altera el rumbo del debate, que se concentra en torno a la comparación entre la oratoria antigua y la moderna. A una presentación de Apro - a favor de los oradores contemporáneos - sigue una de Mesalla — a favor de los antiguos-. El debate se encamina, finalmente, hacia el tema central de la obra, las causas de la decadencia de la elocuencia. Mesalla presenta entonces una serie de falencias morales y educativas como principales factores del declive. Materno, por su parte, cierra la discusión alegando que la verdadera causa de tal decadencia es el cambio en la organización política de la sociedad romana, de república

${ }^{4}$ Véase Vell. I 16-17; Sen., Con. 1 pr. 7; Petr. 1.1 ss.; Sen., Ep. 114.1 ss.

Al respecto, véase R. Güngerich, Kommentar zum Dialogus des Tacitus. Aus dem Nachlaß herausgegeben von H. Heubner, Gotinga, 1980, p. 196 ss. y M. Beck, «Das dramatische Datum des Dialogus de oratoribus. Überlegungen zu einer in Vergessenheit geratenen Streitfrage», RhM 144, 2001, pp. 159-171. 
a imperio. La estructura de la discusión es clara, pese a que todo intento de esquematizarla se ve limitado por la inevitable ambigüedad que introduce la laguna existente entre los capítulos 35 y 36 del texto. Este hiato abarcaría, según la opinión hoy generalmente aceptada, el final del segundo discurso de Mesalla y el principio de la alocución de Materno que cierra la obra ${ }^{6}$.

Los argumentos de los interlocutores se encuentran distribuidos, por tanto, en tres pares de discursos, separados por breves escenas intermedias ${ }^{7}$ :

- proemio (1-5.3)

— primer par de discursos: Apro y Materno sobre oratoria y poesía (5.3-13)

- llegada de Mesalla y cambio del rumbo del debate (14-16.3)

- segundo par de discursos: Apro y Mesalla sobre oratoria antigua y moderna (16.4-26)

— interrupción de Materno (27)

- tercer par de discursos: Mesalla y Materno sobre las causas de la decadencia (28-41)

- cierre (42)

Las diferentes temáticas tratadas en cada pareja de discursos han suscitado una larga discusión académica en torno a la unidad del diálogo y a su verdadero tema. El intercambio inicial entre Apro y Materno se presenta, sobre todo, como problemático, pues el mismo no contiene relaciones directas con el tema planteado por Tácito en el proemio. Las dificultades de interpretación - propias de un texto trasmitido en forma fragmentaria - hacen que la intencionalidad de la obra resulte poco clara para el lector contemporáneo. El talento literario de Tácito dota, además, a cada personaje y cada argumento de un viso de realidad y de una credibilidad indiscutible, que no permiten dejar de lado a ninguno de ellos como un simple complemento ni identificar fácilmente una opinión refrendada por el autor.

${ }^{6}$ La literatura sobre la dimensión de la laguna y la participación o no de Secundo en el debate es vasta, pero la cuestión se considera hoy prácticamente cerrada. Véase Güngerich, Kommentar zum Dialogus des Tacitus, p. 175. Para un resumen de algunas de las posturas más importantes, véase J. Tárrega Garrido, «Secundo y la gran laguna en el Dialogus de oratoribus», $C F C(L)$ 24, 1, 2004, pp. 29-37.

7 Reconocer esta estructura subyacente al debate fue el mérito de Karl Barwick, véase de este autor, «Zur Erklärung und Komposition des Rednerdialogs des Tacitus», en Festschrift W. Judeich zum 70. Geburtstag, überreicht von Jenaer Freunden, Weimar, 1929, pp. 81-108. 
Las teorías sobre la opinión de Tácito en el contexto del Dialogus han girado - con numerosos matices - principalmente en torno a dos extremos opuestos. Para un primer grupo de estudiosos, Tácito expone sus propias ideas por boca de Materno, la figura principal del texto y la que cierra la discusión con la respuesta más convincente a la pregunta planteada en el proemio ${ }^{8}$. Algunos de los defensores de esta interpretación incluso hacen una lectura biográfica del Dialogus, al que ven como un intento de Tácito de legitimar un abandono personal de la oratoria para dedicarse a la historia. Para un segundo grupo de especialistas, por el contrario, Tácito se limita en el Diálogo a exponer diferentes argumentos y puntos de vista sobre el papel y las posibilidades de la elocuencia en la época imperial, pero distanciándose y evitando una identificación precisa de su persona con alguno de ellos. Es decir, Tácito se expresa igualmente a través de todos los interlocutores de la obra' ${ }^{9}$. No han faltado, ciertamente, intentos de identificar la posición de Tácito con lo expuesto por otros de los protagonistas, pero, en comparación con las dos posturas arriba mencionadas, éstos han sido más bien marginales ${ }^{10}$.

${ }^{8}$ Es imposible citar aquí siquiera a un número significativo de los representantes de esta postura ni, mucho menos, hacer mínimamente justicia a los matices y diferencias de sus respectivos argumentos. Especialmente relevantes son: W. Peterson, Cornelii Taciti Dialogus de Oratoribus, Oxford, 1893, p. XXXVIII; R. Hirzel, Der Dialog. Ein literarhistorischer Versuch. Zweiter Theil, Leipzig, 1895 p. 56 s.; Barwick, «Zur Erklärung und Komposition des Rednerdialogs des Tacitus», p. 107; W. Den Boer, «Die gegenseitigen Verhältnisse der Personen im Dialogus de Oratoribus und die Anschauung des Tacitus», Mnemosyne 3, 7, 1939, pp. 218-224; Barwick, «Der Dialogus de Oratoribus des Tacitus», pp. 8-19; Güngerich, Kommentar zum Dialogus des Tacitus, p. 202; D. Flach, Einführung in die römische Geschichtsschreibung, Darmstadt, 1985, p. 203; T. D. Barnes, «The Significance of Tacitus' Dialogus de Oratoribus», HSPh 90, 1986, p. 238 ss.; Bo, Le principali problematiche del Dialogus de Oratoribus, p. 228.

9 Vale aquí también la advertencia expresada en la nota anterior. Especialmente relevantes son: E. Köstermann, «Der taciteische Dialogus und Ciceros Schrift De Re Publica», Hermes 65, 1930, p. 417; Borzák, RE Supp. XI, p. 439; Murgia, «The Date of Tacitus' Dialogus», p. 111; G. Williams, Change and Decline. Roman Literature in the Early Empire, Berkeley-Los ÁngelesLondres, 1978, pp. 26-51; C. O. Brink, «Quintilian's De Causis Corruptae Eloquentiae and Tacitus' Dialogus de Oratoribus», CQ 39, 2, 1989, p. 498 s.; íd., «History in the Dialogus de oratoribus and Tacitus the Historian. A new Approach to an old Source», Hermes 121, 1993, pp. 335-349; T. J. Luce, «Reading and Response in the Dialogus», en T. J. Luce y A. J. Woodman (eds.), Tacitus and the Tacitean Tradition, Princeton, 1993, p. 35 s.

${ }^{10}$ Véase por ejemplo C. D. N. Costa, «The Dialogus», en T. A. Dorey (ed.), Tacitus, Nueva York, 1969, p. 31. En este artículo se argumenta que las ideas de Tácito se aproximarían más a las de Apro. 
La controversia académica ha contribuido en muchos aspectos a oscurecer, antes que a esclarecer, las principales problemáticas planteadas por esta obra. Muchos puntos - a mi juicio, indiscutibles - han sido en reiteradas oportunidades cuestionados por distintos especialistas. Es necesario entonces, en primer lugar, plantear algunas premisas generales sobre lo que el Dialogus permite reconocer acerca de la opinión de su autor. El marco que debe servir de punto de partida en esta indagación es, sin duda, el hecho generalmente aceptado de que Tácito comparte la idea central de una decadencia de la oratoria imperial respecto de los estándares de aquélla en la época republicana $^{11}$. Esto es evidente y el hecho de destacarlo sería innecesario, de no ser por los intentos de algunos investigadores por ponerlo en duda. En efecto, S. M. Goldberg ha argumentado que «the decline of oratory becomes a question which Tacitus never answers in his own voice, and his reluctance to do so is not the result of false modesty. He instead is putting distance between what has become Fabius' statement of the theme and what might be his own opinion on the subject» ${ }^{12} \mathrm{y}$, más adelante, «he conjures up a previous generation of speakers in order to avoid responsibility for what they say» ${ }^{13}$. Goldberg pretende que los recursos literarios elegidos por Tácito - es decir, el planteo de responder a un requerimiento de su amigo Fabio Justo y la elección de oradores de la generación previa como protagonistas de la discusión- implican un distanciamiento del autor respecto de la temática planteada y de los argumentos esgrimidos en el texto. Esta opinión debe ser rechazada.

El proemio del Diálogo presenta una situación que es, con toda probabilidad, ficcional. No obstante, ésta debía ser creíble para los lectores contemporáneos. El hecho de que Fabio pretenda, de parte de Tácito, una disertación sobre las causas de la decadencia de la elocuencia implica, ciertamente, un consenso general de este último sobre esa premisa. De lo contrario, cabría esperar que Tácito ofreciera a su amigo antes una refutación de esta tesis que una exposición de sus causas. Finalmente, cabe añadir que la mencionada

${ }^{11}$ Véase, por ejemplo, Williams, Change and Decline, p. 49. Cf. Barnes, «The Significance of Tacitus' Dialogus de Oratoribus», p. 232: «The Dialogus does not discuss the decline of oratory: it assumes it». Véase también Luce, «Reading and Response in the Dialogus», p. 19; K. Heldmann, Antike Theorien über Entwicklung und Verfall der Redekunst, Múnich, 1982, p. 163.

${ }^{12}$ S. M. Goldberg, «Appreciating Aper: The Defence of Modernity in Tacitus' Dialogus de oratoribus», $C Q 49,1,1999$, pp. 225-226.

${ }^{13}$ Ibíd., p. 226. 
elección de oradores de una generación pasada como protagonistas es un recurso típico del género dialógico elegido por el autor. Con él no se pretende principalmente un distanciamiento de los argumentos expuestos, sino, sobre todo, captar la benevolencia del lector con una declaración de modestia y, al mismo tiempo, dotar a la argumentación de una mayor autoridad. Tácito declara expresamente en el proemio que apenas se atrevería a responder la pregunta planteada por Fabio, si tuviera que exponer sus propias ideas y no repetir lo expuesto por hombres especialmente elocuentes, a los que pudo escuchar en su juventud ${ }^{14}$. Esto equivale a decir que él podría exponer sus propias razones si no lo impidiese su modestia. Es claro que Tácito concuerda con la tesis planteada y tiene una opinión personal sobre las causas del proceso.

Ahora bien, si Tácito acepta la idea de una decadencia de la oratoria, es evidente entonces que Apro - el participante del Diálogo que niega la inferioridad de los oradores contemporáneos respecto de los antiguos - no puede ser considerado como un vocero privilegiado de su posición. Ello no significa, sin embargo, que los argumentos de este personaje sean irrisorios y simples oposiciones de los expresados por los demás interlocutores, como ha sido argumentado por algunos estudiosos ${ }^{15}$. Por el contrario, Tácito lo caracteriza cuidadosamente y hace de él un contrincante digno y a la altura del debate ${ }^{16}$. Mesalla y Materno serían, indudablemente, los candidatos más plausibles para presentar ideas cercanas a las del autor. Algunos especialistas han querido ver en el Mesalla del Dialogus un vocero de las tesis de Quintiliano sobre los factores educativos de la decadencia oratoria. Esta tesis cuenta con cierta probabilidad, pero nuestro casi completo desconocimiento de la obra De causis corruptae eloquentiae, del gran retórico romano, impide alcanzar ninguna certeza sobre este punto ${ }^{17}$.

Antes que Mesalla, es, sin duda, Materno el personaje en el que Tácito descarga la responsabilidad de exponer la respuesta más convincente al problema planteado. El autor le reserva el discurso final, lo que es una clara señal de que los argumentos por él expuestos constituyen el clímax de la obra.

\footnotetext{
${ }^{14} 1.2$.

${ }^{15}$ Véase Williams, Change and Decline, p. 28 y Barnes, «The Significance of Tacitus' Dialogus de Oratoribus», p. 237.

${ }^{16} \mathrm{Al}$ respecto, véase C. Champion «Dialogus 5.3-10.8: A Reconsideration of the Character of Marcus Aper», Phoenix 48, 2, 1994, pp. 152-163. Con ciertos recaudos, véase también Goldberg, «Appreciating Aper».

${ }^{17} \mathrm{Al}$ respecto, véase Brink, «Quintilian's De Causis Corrupate Eloquentiae and Tacitus' Dialogus de Oratoribus».
} 
Todo ello no significa, sin embargo, que lo declarado por Materno deba verse como un reflejo exacto de la opinión personal de Tácito, tal como pretenden los que abogan por una lectura biográfica del Diálogo. Para ellos, el retiro de Materno del foro - para concentrarse en la poesía - es expresión de un idéntico retiro de Tácito del mismo ámbito para consagrarse a otra actividad literaria, la escritura de las historiae ${ }^{18}$. Pero la ficción no puede traducirse literalmente en biografía. Pese a las voces críticas que han impugnado esta interpretación con argumentos contundentes ${ }^{19}$, ésta sigue siendo defendida en publicaciones recientes ${ }^{20}$. Una fuente que descalifica en forma casi categórica tal lectura fue señalada por diversos autores ya hace tiempo ${ }^{21}$. Se trata de un pasaje de una carta de Plinio el Joven al autor del Diálogo que muestra a este último rodeado de numerosos alumnos, de entre los cuales Plinio le ruega que escoja uno para que se desempeñe como profesor de retórica en $\mathrm{Como}^{22}$. Tácito siguió, en consecuencia, ocupado con la retórica aun después de la escritura del Dialogus ${ }^{23}$.

Quienes reconocen en Materno la opinión de Tácito tienen razón en considerarle un interlocutor privilegiado dentro de la obra, pero se equivocan al creer que lo expuesto por él puede identificarse exactamente con el pensamiento del autor. Las limitaciones de la lectura biográfica del Dialogus lo muestran claramente. Por su parte, quienes entienden que Tácito se expresa igualmente a través de todos los participantes del debate no caen en ese error,

${ }^{18}$ Esta lectura biográfica es argumentada por Barwick, «Der Dialogus de oratoribus des Tacitus. Motive und Zeit seiner Entstehung», p. 31. Con ella concuerda R. Syme, Tacitus, Oxford, 1958, p. 111 y pp. 672-673.

${ }^{19}$ Véanse las demoledoras críticas de Brink, «Can Tacitus' Dialogus Be Dated?», p. 271 ss.

${ }^{20}$ Véase R. Mayer, Tacitus. Dialogus de Oratoribus. Cambridge Greek and Latin Classics, Cambridge, 2001, p. 8.

${ }^{21}$ Véase, por ej., Köstermann, «Der taciteische Dialogus und Ciceros Schrift De Re Publica», p. 417.

${ }^{22}$ Plin., Ep. IV 13.10: iniungo autem et oro rei magnitudini rogo, ut ex copia studiosorum, quae ad te ex admiratione ingenii tui conuenit, circumspicas praeceptores, quos sollicitare possimus, sub ea tamen condicione ne cui fidem meam obstringam.

${ }^{23} \mathrm{La}$ datación de esta carta correspondería, según los indicios cronológicos del libro IV de la correspondencia pliniana, al período entre 103-105 d. C., es decir, sería posterior a la redacción del Dialogus. Una síntesis de los argumentos de los diversos especialistas sobre la datación de este libro de la correspondencia pliniana en E. Aubrion, «La "Correspondance" de Pline le Jeune: Problèmes et orientations actuelles de la recherche», ANRW 2.33.1, 1989, p. 317 ss. 
pero fallan al no reconocer la jerarquía existente entre los argumentos de los diversos personajes. Los primeros realizan una identificación demasiado automática, mientras que los segundos niegan prácticamente la existencia de una opinión propia del autor.

Existe otra vía de aproximación a este problema. Recientemente, D. S. Levene ha argumentado, en un estimulante artículo, que los discursos del Dialogus comparten, pese a sus divergencias en otros aspectos, una única versión de historia literaria ${ }^{24}$. Un consenso implícito une en este punto a los interlocutores: ellos presentan diferentes respuestas al problema planteado en el proemio de la obra, pero sus discursos desarrollan, en opinión de este especialista, un único y complejo relato del desarrollo histórico de la literatura en Roma. La existencia de elementos de coincidencia entre los participantes del debate es un hecho conocido, pero que no ha recibido, en mi opinión, la consideración debida. En efecto, un análisis de los discursos desde esta perspectiva revela la existencia de un consenso general en la obra sobre los tipos de factores que explican la divergencia de la oratoria contemporánea respecto de la antigua. Semejanzas con pasajes de otras obras de Tácito señalan, además, que a través de ese consenso nos acercamos a la opinión del autor sobre el problema tratado en el Dialogus.

Es evidente que tanto Apro como Mesalla y Materno concuerdan en que la oratoria contemporánea se diferencia de la antigua. El primero expresa esta idea claramente: Agere enim fortius iam et audentius uolo, si illud ante praedixero, mutari cum temporibus formas quoque et genera dicendi ${ }^{25}$. La elocuencia no presenta un único e inmutable rostro, sino que se transforma con la sucesión de las épocas ${ }^{26}$. Este punto es aprobado tácitamente por Materno y expresamente por Mesalla, pero, en el caso de este último, con la salvedad de que los rostros de la elocuencia también difieren dentro de un mismo período ${ }^{27}$. El cambio no está en discusión, sino su valoración. Apro

${ }^{24}$ D. S. Levene, «Tacitus' Dialogus as Literary History», TAPhA 134, 2004, pp. 157200.

2518.2 .

${ }^{26}$ 18.3: Nec quaero quis disertissimus: hoc interim probasse contentus sum, non esse unum eloquentiae uultum, sed in illis quoque quos uocatis antiquos pluris species deprehendi, nec statim deterius esse quod diuersum est, uitio autem malignitatis humanae uetera semper in laude, praesentia in fastidio esse.

${ }^{27}$ 25.2: ne illi quidem parti sermonis eius repugno, si comminus fatetur pluris formas dicendi etiam isdem saeculis, nedum diuersis extitisse. 
niega la decadencia, pero no argumenta que la oratoria contemporánea sigue manteniendo los estándares de la república tardía. Él reconoce un cambio esencial en la forma imperial de elocuencia, pero ve en el mismo, a diferencia de sus interlocutores, un avance. Los restantes participantes del debate lo consideran, por el contrario, un distanciamiento de la excelencia clásica alcanzada en la época de Cicerón.

Un análisis más detallado de los diferentes argumentos revela, sin embargo, que el consenso entre los interlocutores no se limita a ese punto. De hecho, todos comparten una explicación similar de esa mutación en las formas de la elocuencia, sólo que colocando el acento en aspectos distintos. Ninguno considera el cambio como un producto de tendencias de desarrollo internas de la oratoria; todos lo ven como el resultado de una adaptación de ésta ante una transformación de factores externos. Lo que distingue sus argumentaciones es la elección diferente, realizada en cada caso, de un factor preponderante como causa de ese cambio.

Para Apro, la oratoria debió modificarse necesariamente para adecuarse a las circunstancias de la época y a los nuevos gustos del público, un proceso que se inició con Cassio Severo. Los oyentes de la época imperial ya no son tan incultos como los de la república; como consecuencia de la difusión de los estudios literarios, mucho de lo que antes garantizaba el éxito de un orador ahora produce, en cambio, hastío:

Vidit (sc. Cassius Seuerus) namque, ut paulo ante dicebam, cum condicione temporum et diuersitate aurium formam quoque ac speciem orationis esse mutandam. facile perferebat prior ille populus, ut imperitus et rudis, impeditissimarum orationum spatia, atque id ipsum laudabat, si dicendo quis diem eximeret ${ }^{28}$.

Y, más abajo, añade:

At hercule peruulgatis iam omnibus, cum uix in corona quisquam adsistat, quin elementis studiorum, etsi non instructus, at certe imbutus sit, nouis et exquisitis eloquentiae itineribus opus est, per quae orator fastidium aurium effugiat $^{29}$.

${ }^{28} 19.3$.

${ }^{29} 19.5$. 
El hecho de que Apro ve al público y sus gustos como el factor determinante en la transformación de la elocuencia es claramente visible en su argumentación. Ejemplo de ello es su comparación entre oratoria y actuación teatral: un estilo arcaico ya no es tolerado en el foro del mismo modo que, en el teatro, el público rechazaría a un actor que quisiera expresarse en el escenario como sus pares de la república tardía ${ }^{30}$. El público es, para Apro, el causante del progreso de los oradores contemporáneos; éstos han avanzado en belleza y ornamento al regirse por los oídos y el juicio del auditorio ${ }^{31}$. Cuando Apro afirma que no puede culparse a Corvino por no haber alcanzado el brillo de la época imperial ${ }^{32}$, vemos lo estrecha que es esa conexión para él. Conforme a la lógica de su argumentación, resulta claro que considera que esa posibilidad de superación no estaba en poder de Corvino al carecer éste de la influencia de un público más cultivado.

Mesalla impugna la valoración hecha por Apro de la elocuencia contemporánea. Pero también reconoce - como se ha dicho - una transformación en la oratoria, producto de una alteración de factores externos. La diferencia estriba en que para él las causas del cambio son otras: una drástica $-\mathrm{y}$ negativa - modificación de los estándares morales y educativos de la sociedad imperial en comparación con los de la era republicana. Mesalla resume su argumento con claridad en un breve pasaje, en el que descarta, además, que la decadencia pueda deberse a una falta de talentos:

Quis enim ignorat et eloquentiam et ceteras artis desciuisse ab illa uetere gloria non inopia hominum, sed desidia iuuentutis et neglegentia parentum et inscientia praecipientium et obliuione moris antiqui? $?^{33}$

Este personaje reconoce, sin embargo, que existen otras causas de este proceso, cuyo desarrollo deja a sus interlocutores.

Materno, finalmente, coincide en la evaluación hecha por Mesalla pero ve las causas de esa misma decadencia en la transformación política del Estado romano con el paso de la república al principado —antes que en el gusto

${ }^{30}$ 20.3: Vulgus quoque adsistentium et adfluens et uagus auditor adsueuit iam exigere laetitiam et pulchritudinem orationis; nec magis perfert in iudiciis tristem et impexam antiquitatem quam si quis in scaena Roscii aut Turpionis Ambiuii exprimere gestus uelit.

${ }^{31} 20.6$.

3221.9 .

${ }^{33} 28.2$. 
del público o en los estándares educativos y morales de la época-. La gran elocuencia necesita del contexto de turbulencia y conflicto que caracterizó la república tardía, en el que los temas tratados y los premios al alcance de los oradores eran mucho mayores que en un Estado ordenado como el que existe en el principado:

Magna eloquentia, sicut flamma, materia alitur et motibus excitatur et urendo clarescit. Eadem ratio in nostra quoque ciuitate antiquorum eloquentiam prouexit $^{34}$.

El punto de inflexión que señala el fin de la oratoria es, para Materno, naturalmente el reinado de Augusto, en el que una prolongada quietud, la continua inactividad del pueblo, la permanente tranquilidad del senado y, sobre todo, la disciplina impuesta por el príncipe redujeron la elocuencia, tal como hicieron con todas las demás cosas ${ }^{35}$.

Pero Materno - contrariamente a lo que podría esperarse de un personaje que, al principio de la obra, es presentado como un crítico severo de la realidad política contemporánea - no lleva a cabo una valoración negativa de este cambio político y de la decadencia y pérdida de la elocuencia. En su opinión, la oratoria de los Gracos no fue tan valiosa para la república como para justificar las leyes que éstos impusieron, ni a Cicerón le compensó la fama de sus discursos su triste final. La gran y notable elocuencia es hija de la licencia, a la que los estúpidos llaman libertad ${ }^{36}$. La oratoria es, en consecuencia, en el contexto del Estado imperial, casi obsoleta, y eso legitima la elección - expresada por Materno en su primer discurso- de dejar de lado las tareas del foro para concentrarse exclusivamente en la poesía.

Un último punto central de la argumentación de Materno necesita ser destacado. Para él —al igual que para Mesalla—, tal decadencia de la oratoria no es producto de la falta de talentos, sino de los límites impuestos por el nuevo contexto político. En efecto, Materno afirma que, si los oradores antiguos

${ }^{34}$ 36.1. Véase también 37.8 .

35 38.2: postquam longa temporum quies et continuum populi otium et assidua senatus tranquillitas et maxime principis disciplina ipsam quoque eloquentiam sicut omnia alia pacauerat.

36 40.2: sed est magna illa et notabilis eloquentia alumna licentiae, quam stulti libertatem uocitant, comes seditionum, effrenati populi incitamentum, sine obsequio, sine seueritate, contumax, temeraria, adrogans, quae in bene constitutis ciuitatibus non oritur. 
hubieran vivido en la época imperial no hubiesen brillado en igual medida a lo que lo hicieron, mientras que, si los oradores actuales hubieran vivido durante la república, se hubiesen destacado igual que aquéllos ${ }^{37}$.

Para los tres interlocutores, el desarrollo de la elocuencia está — según puede deducirse de sus argumentos - rigurosamente determinado por los imperativos de su contexto social e histórico. Todos coinciden en este punto, por más que cada uno de ellos destaque factores diferentes como preponderantes en ese condicionamiento. A juicio de los tres, el rumbo de la elocuencia está fijado a tal punto por ese marco que los talentos individuales no desempeñan ningún papel relevante. Incluso un intercambio de los oradores de diferentes épocas no alteraría el resultado, como vimos que alega Materno. En esta visión, la idea de decadencia pierde bastante su sentido, pues sólo se entiende que ella supone una adecuación inevitable de la elocuencia (uno podría incluso decir necesaria) a un nuevo contexto socio-político. Se trata casi de un determinismo histórico: los oradores son simplemente víctimas de los férreos límites impuestos por sus respectivas épocas. Naturalmente, existe cierta tentación de ver en este extraño consenso implícito una línea de pensamiento del propio Tácito, que se impone aun por encima de las tesis enfrentadas asignadas a cada personaje. Y, si bien el argumento no puede considerarse concluyente, creo que supera la simple identificación hecha entre Tácito y Materno, y también la poco útil afirmación de que hay algo del autor en todos los personajes.

La comparación de estas ideas con algunos pasajes de los Annales refuerza la tesis aquí propuesta, esto es, que ese consenso entre los interlocutores del Dialogus respondería, en cierta medida, a una visión de Tácito. En efecto, en diversos pasajes de la principal obra de este historiador se sugiere que las diferentes características de la república tardía y del principado determinan estrictamente el comportamiento de los individuos. Ello es claro, por ejemplo, en el discurso puesto en boca de Asinio Galo en rechazo de una legislación suntuaria que figura en el libro II. En él se presenta la moderación de la república en ese sentido como consecuencia de la pobreza del Estado $y$, a su vez, se estima que los excesos de la época imperial son resultado de la expansión y de los amplios dominios en posesión del pueblo romano ${ }^{38}$.

3741.5 .

${ }^{38}$ Ann. II 33.3: auctu imperii adoleuisse etiam priuatas opes, idque non nouum, sed e uetustissimis moribus: aliam apud Fabricios, aliam apud Scipiones pecuniam; et cuncta ad rem publicam referri, qua tenui angustas ciuium domos, postquam eo magnificentiae uenerit, gliscere singulos. 
Todavía más explícito es un pasaje del libro III en el que, en una supuesta carta de Tiberio al senado, se utiliza un argumento similar para rechazar otro intento legislativo para restringir el lujo ${ }^{39}$. Con motivo de este nuevo rechazo de una ley suntuaria, Tácito introduce un breve excurso sobre las causas que llevaron, en períodos posteriores, a una efectiva restricción de la suntuosidad de las clases altas del imperio ${ }^{40}$. Este análisis induce al autor a considerar la explicación alternativa, esto es, que existen ciclos fatales que determinan los asuntos humanos:

nisi forte rebus cunctis inest quidam uelut orbis, ut quem ad modum temporum uices, ita morum uertantur; nec omnia apud priores meliora, sed nostra quoque aetas multa laudis et artium imitanda posteris tulit ${ }^{41}$.

La noción de que la época determina las acciones de los hombres aparece en este caso conectada con un rechazo de la idea - típica en la mentalidad romana - de la necesaria primacía de lo antiguo - parecer cercano a lo afirmado por Apro- ${ }^{42}$. En este pasaje el determinismo es relacionado con su correlato lógico de relativismo, en forma más clara que en el Dialogus.

Otra clara coincidencia es presentada por un breve excurso del libro IV, en el que Tácito fundamenta la diferencia entre los temas menos interesantes tratados por él y aquellos más atractivos expuestos por los historiadores de la república, fundamentación que descansa en las diferentes características de cada período:

Pleraque eorum quae rettuli quaeque referam parua forsitan et leuia memoratu uideri non nescius sum: sed nemo annales nostros cum scriptura eorum contenderit qui ueteres populi Romani res composuere. Ingentia illi bella, expugnationes urbium, fusos captosque reges, aut si quando ad interna praeuerterent, discordias consulum aduersum tribunos, agrarias frumentariasque leges, plebis et optimatium certamina libero egressu memorabant: nobis in arto et inglorius labor; immota quippe aut modice lacessita pax, maestae urbis res et princeps proferendi imperi incuriosus erat ${ }^{43}$.

${ }^{39}$ Ann. III 54.5: cur ergo olim parsimonia pollebat? quia sibi quisque moderabatur, quia unius urbis ciues cramus; ne inritamenta quidem eadem intra Italiam dominantibus. Externis uictoriis aliena, ciuilibus etiam nostra consumere didicimus.

${ }^{40}$ Ann. III 55.2-5.

${ }^{41}$ Ann. III 55.6.

42 Idea repetida por Tácito en Ann. III 88.

${ }^{43}$ Ann. IV 32.7 
El imperio ha privado a sus historiadores de los grandes temas de que dispusieron aquellos que se ocuparon de narrar los sucesos de la república. Tácito realiza aquí un diagnóstico muy similar al expuesto por Materno acerca de la oratoria: el contexto histórico — es decir, la diferencia radical entre república e imperio- determina el carácter de su obra y le fija límites estrechos. La cercanía con el Dialogus es indiscutible ${ }^{44}$. Otros fragmentos de los Annales revelan esta inclinación de Tácito a un cierto determinismo o fatalismo cercano a lo expuesto por los interlocutores del Dialogus de oratoribus - a los que remito a fin de no abundar en citas $-{ }^{45}$.

En conclusión, el Diálogo sobre los oradores es una obra maestra del género dialógico latino. El talento de Tácito para caracterizar a los personajes y dotarlos de argumentos convincentes - junto con la transmisión fragmentaria del texto- ha hecho compleja la interpretación de la obra y ha tornado difícil el identificar una opinión clara refrendada por su autor. Un análisis detallado de los distintos argumentos de los interlocutores puede, sin embargo, distinguir un consenso general subyacente al debate, susceptible de ser relacionado con el pensamiento de su redactor. La perspectiva cercana a un determinismo histórico, reconocible en el Dialogus, evidencia el parentesco cercano de este opúsculo con el conjunto de la obra tacitea. Las similitudes en las perspectivas del Diálogo y de algunos pasajes de los Annales refuerzan la tesis aquí propuesta de ver ese consenso como producto de la opinión general de Tácito (o, por lo menos, de ciertas facetas de su pensamiento) sobre las posibilidades de la elocuencia y otros géneros literarios en el régimen imperial. El nuevo contexto político generado por la concentración del poder en una sola persona impide, en su concepción, tanto a historiadores como a oradores realizar producciones comparables a las de la era republicana.

\section{Fecha de recepción de la primera versión del artículo: 12/12/2007 Fecha de aceptación del artículo: 18/06/2008 \\ Fecha de recepción de la versión definitiva del artículo: 10/09/2008}

\footnotetext{
${ }^{44}$ Por otra parte, en Ann. II 87 Tácito se refiere a las dificultades y riesgos de la oratoria en el reinado de Tiberio, otra coincidencia con Materno.

${ }^{45}$ Véase Ann. VI 22 donde Tácito parece inclinarse a una visión cercana al fatalismo planteado por los estoicos. Sobre la inclinación de Tácito al fatalismo, véase H. Furneaux, The Annals of Tacitus, Oxford, $1896^{2}$, p. 29 ss. Véase también F. Galtier, «Le rôle des dieux dans les Opera Maiora de Tacite», Acta Antiqua 45, 4, 2005, pp. 413-422.
} 